\title{
Research on Seismic Test and Calculation Model for Improving Factor of Composite Board with Heat Preservation Function
}

\author{
Shaochun Ma ${ }^{1,2}$ and Hongyuan Fang ${ }^{1}$ \\ ${ }^{1}$ College of Water Conservancy \& Engineering, Zhengzhou University, Zhengzhou 450001, China \\ ${ }^{2}$ School of Civil Engineering and Architecture, Henan University, Kaifeng 475004, China \\ Correspondence should be addressed to Shaochun Ma; scma@vip.henu.edu.cn
}

Received 21 February 2021; Revised 5 April 2021; Accepted 13 April 2021; Published 23 April 2021

Academic Editor: Xia Bian

Copyright (c) 2021 Shaochun Ma and Hongyuan Fang. This is an open access article distributed under the Creative Commons Attribution License, which permits unrestricted use, distribution, and reproduction in any medium, provided the original work is properly cited.

\begin{abstract}
Since the composition and stress state of thermal-insulation composite plates are extremely complex, it is difficult to conduct calculation using conventional methods. Further calculation on its composition structure is even more difficult. To settle this difficulty, this paper conducted experimental investigations on thermal-insulation composite plate and conventional composite plates, and a simplified calculation method with improved factors was deduced based on the experimental results. In this study, the influence of nonstructural thermal insulation system on the composite plate was specially considered. The calculated expressions are deduced, while the stiffness and damping (properties) are determined. Case analysis was carried out to validate the reliability and accuracy of the simplified calculation method of improvement factor. The research results indicate that the modeling difficulty and computational effort are greatly reduced, with relatively small errors. Hence, it is beneficial to the calculation and analysis of composite plates and global structures.
\end{abstract}

\section{Introduction}

Thermal-insulation composite plates consisted of conventional composite plates and thermal insulation systems [1]. Conventional composite plates are formed by filling concrete in the pores of plaster plates [2]. Polyphenyl insulation plate and outside plasterboard shields construct the thermal insulation system of composite plates. The thermal insulation system makes the composite plate have the ability of heat insulation, thus, achieving the purpose of building energy conservation $[3,4]$. During the normal operation of composite plates, the thermal insulation system can not only protect composite plates from erosion of severe environment, but also extend the service life of composite plates [5]. Plaster plates have good flatness and can be directly used as the leveling course of building outside finish, as well as avoiding the out leakage of thermal insulation plates. Plaster plates protect and isolate thermal insulation plates at the same time. Hence, they can block the spread of fire during the breaking out of fire $[6,7]$. Hence, applications of green energy saving plaster and polyphenyl materials are wide, which can promote the innovation of new wall types around the world [8].

In practical engineering, the structural load is mainly born by conventional composite plates. The thermal insulation system, as the envelope enclosure, is the secondarily stressed nonbearing unit [9]. The load applying on the outsider thermal insulation system is relatively small, or even no load is applied. Hence, during analyzing composite plates, the influence of thermal insulation system is usually ignored. Also, reliability design of nonstructural units still draws few attentions from designers [10]. However, scholars around the world have conducted massive experiments on similar composite plates [11-14]. The results indicated that the bearing and deformation capacities of composite plates with thermal insulation systems are slightly higher than those of conventional composite plates [15]. Hence, during analyzing this type of composite plates, it is unscientific to ignore the influence of the thermal insulation system. 
A calculated model for the engineered cementitious composite reinforced walls was proposed by Ref. [16], and it can be used to calculate and estimate the maximum lateral strength. Literature [17] presents the seismic assessment of the Cathedral of Matera in southern Italy, and modal identification tests were performed in order to identify and characterize the main dynamic properties of the structure. Literature [18] concludes with a statistical analysis of the seismic damage conducted with the tool of Damage Probability Matrixes (DPM) and fragility curves. The results of these assessments can be used to establish criteria for the restoration and reinforcement of buildings.

In this paper, experimental investigations were conducted on thermal-insulation composite plate and conventional composite plates, and a simplified calculation method of improvement factors was deduced based on experimental results. Thus, the difficulty in the calculation of complex composite plates is settled, and the influence of thermal insulation system is also considered. The research results are of great importance for the further calculation of thermal-insulation composite components and more complex structures and can provide important references for the study of similar plates and structures.

\section{Experimental Setup}

2.1. Component Design. Figure 1 is a schematic diagram of a composite board. Thermal-insulation composite plates consist of bidirectional porous plasterboard, hidden beams, embedded columns, and thermal insulation systems. Figure 2 is the planar view. The diameter of rebars in composite plates and load beams is all $14 \mathrm{~mm}$. Rebars in the fixed beam of the component bottom are mainly load-bearing rebars (diameter of $20 \mathrm{~mm}$ ) and stirrup rebars (diameter of $8 \mathrm{~mm}$ ). Figure 3 is the front reinforcement diagram. The thickness of thermal-insulation plates is $120 \mathrm{~mm}$, and the thickness of plaster plates is $13 \mathrm{~mm}$. The material test results are listed in Table 1.

Figure 4 shows the test apparatus for composite plates. The loading system contains one horizontal loader and two vertical loaders. The measurement system mainly consists of a horizontal displacement meter, a load sensor, a dial indicator, and the strain gauges for different materials. The specimen fixation system mainly consists of bottom compression beam, top beam, and pull rods. The load control system contains a loading control system (earlier stages) and a displacement control system (later stages). Tests are conducted by strictly following regulations described in Ref. [19].

The material test results of polystyrene insulation boards are listed in Table 1. Specimen of polystyrene board is of diameter $39.1 \mathrm{~mm}$, with $80 \mathrm{~mm}$ high cylinder of polystyrene. The results of the triaxial shear test of polystyrene insulation board are shown in Figures 5 and 6 .

\subsection{Test Results}

2.2.1. Bearing Capacity and Deformation. Under cyclic loading, three thermal-insulation composite plates were tested, with the stress states and deformation of specimens

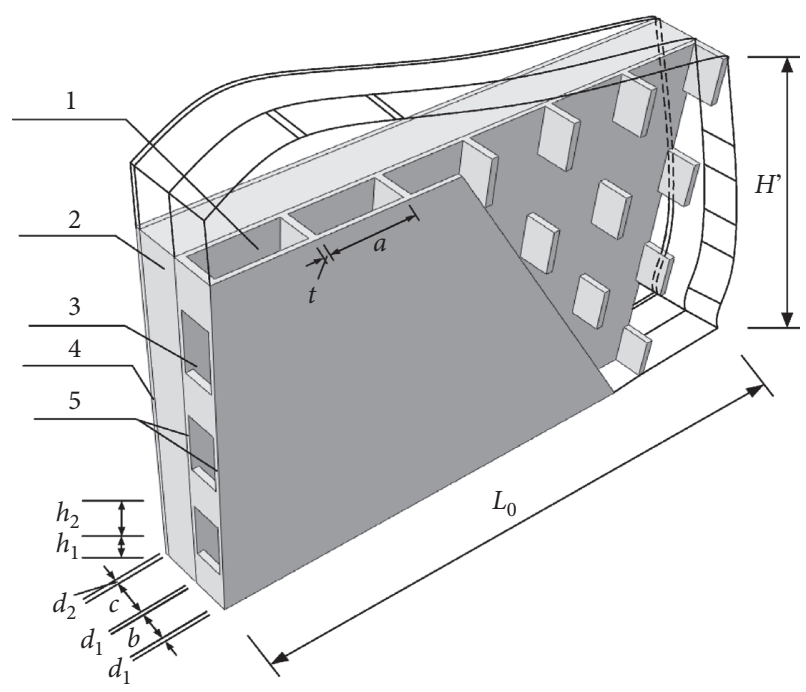

FIgURE 1: Schematic diagram of composite board. Notes: 1, vertical gypsum cavity; 2 , insulation board; 3 , horizontal gypsum cavity; 4 , externally bonded single gypsum board; 5 , gypsum board.

obtained. The force-displacement curves (hysteretic and skeleton) are shown in Figure 7, while test data is summarized in Table 2. The tests results of conventional composite plates without thermal insulation system refer to those reported in Ref. [2]. Based on the comparison, it is implied that the increasing tendency of the force-displacement curves of two types of composite plates is all nonlinear. Compared to conventional composite plates, the stress magnitudes of key points are increased by 1.19, 1.02, and 1.18 times, for thermal-insulation composite plates. Meanwhile, the deformation magnitudes of key points of thermalinsulation composite plates are improved by 1.14, 1.20, and 1.44 times, respectively. The test results indicate that if the thermal insulation system can cooperatively work with conventional composite plates, the global strength and stiffness of composite plates can be effectively improved. Moreover, the elastic-plastic deformation capacity of composite plates can also be enhanced to a certain degree. That is, the global earthquake resistance of thermal-insulation composite plates has an advantage over that of conventional composite plates. According to the skeleton curves displayed in Figure 8, similar conclusions can be drawn.

Figure 9 are the destruction graphs of thermal-insulation composite plates. By comparing and analyzing the destruction diagram of the composite wallboard with thermal insulation function, it can be found that the oblique crack in the direction of $45^{\circ}$ is generated on the thermal insulation board, as shown in Figure 9. Or the separation phenomenon has basically occurred between the insulation board and the main structure of the composite board. It shows that the nonstructural insulation system can improve the bearing and deformation capacity of the composite board. During the seismic test of the composite panel, the insulation system was able to bear part of the load and played a beneficial role. Hence, during analyzing this type of composite plates, it is unscientific to ignore the influence of the thermal insulation system. 


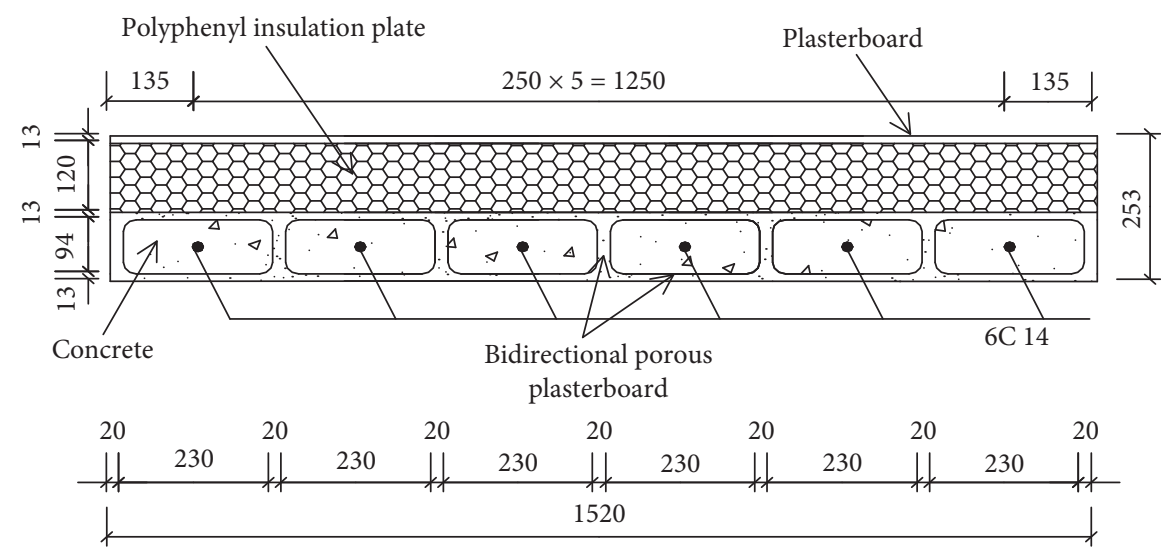

Figure 2: Planar view.

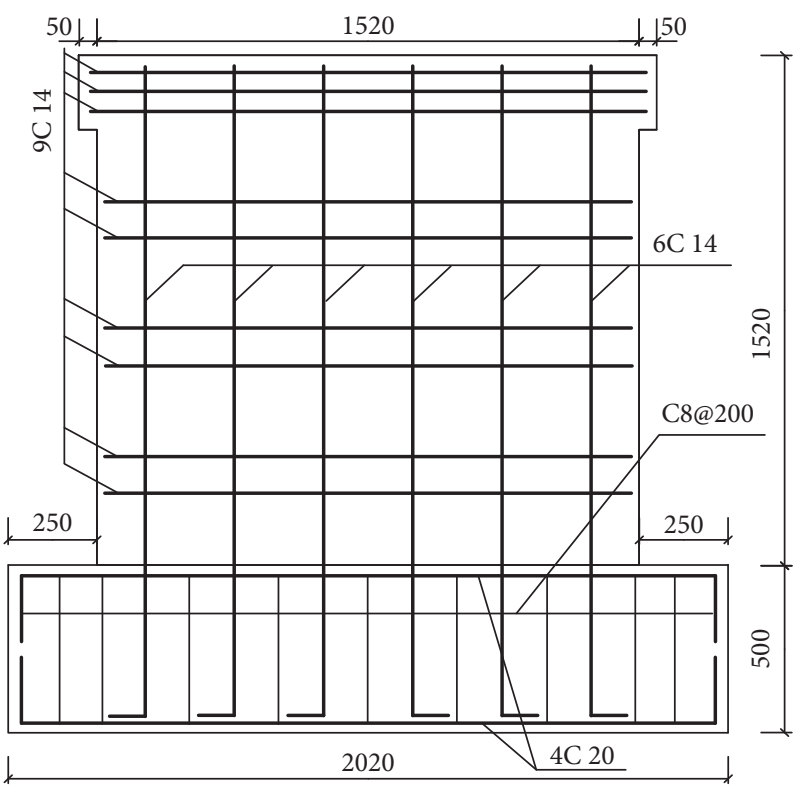

Figure 3: The front reinforcement diagram.

TABLE 1: Material mechanical properties.

\begin{tabular}{|c|c|c|c|c|c|c|c|}
\hline \multirow{2}{*}{ Material properties } & & \multirow{2}{*}{ Plaster } & \multirow{2}{*}{ Concrete } & \multirow{2}{*}{ Thermal insulation plate } & \multicolumn{3}{|c|}{ Rebar } \\
\hline & & & & & $\mathrm{C} 8$ & $\mathrm{C} 14$ & $\mathrm{C} 20$ \\
\hline Compressive strength & $\mathrm{N} / \mathrm{mm}^{2}$ & 5.52 & 24.63 & 0.206 & - & - & - \\
\hline Tensile strength & $\mathrm{N} / \mathrm{mm}^{2}$ & 0.368 & 1.642 & 0.22 & 654.00 & 669.45 & 676.92 \\
\hline Elastic modulus & $\mathrm{N} / \mathrm{mm}^{2}$ & 4350 & 27200 & 2.3 & & 200000 & \\
\hline Density & $\mathrm{kg} / \mathrm{m}^{3}$ & 1400 & 2500 & 33 & & 7850 & \\
\hline
\end{tabular}

2.2.2. Bearing Capacity and Deformation. The average ductility coefficients of composite wallboard with thermal insulation function and ordinary composite wallboards are shown in Table 3, which are 4.22 and 3.55, respectively. Compared with the two composite wallboards, the ductility coefficient is increased by $18.87 \%$. It shows that the ductility of composite wallboard with thermal insulation function is relatively better than that of ordinary composite wallboard. The implication is that composite wall panels with thermal insulation function are better than ordinary composite wall panels in terms of elastoplastic deformation, energy consumption, and seismic performance. The same conclusion can be drawn. In the calculation and analysis of such composite panels, it is unscientific to ignore the influence of the insulation system.

\section{Simplified Calculation Theory}

As widely recognized, to meet the seismic requirement, architectural structures not only have to possess enough 


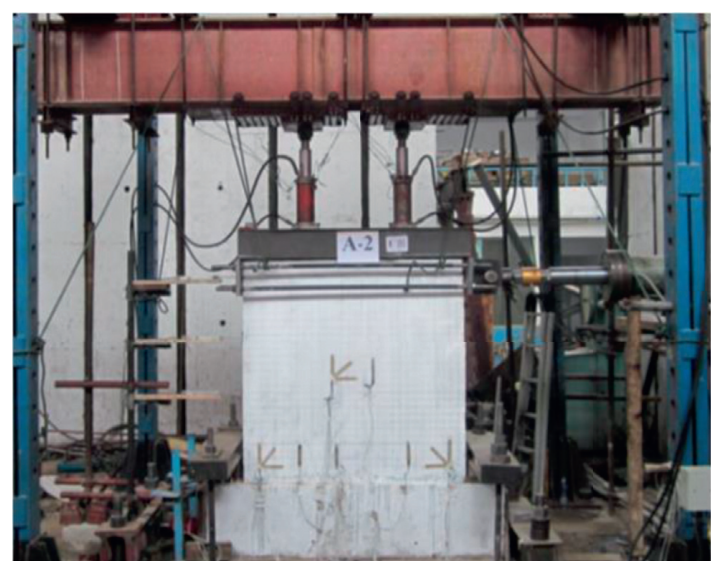

(a)

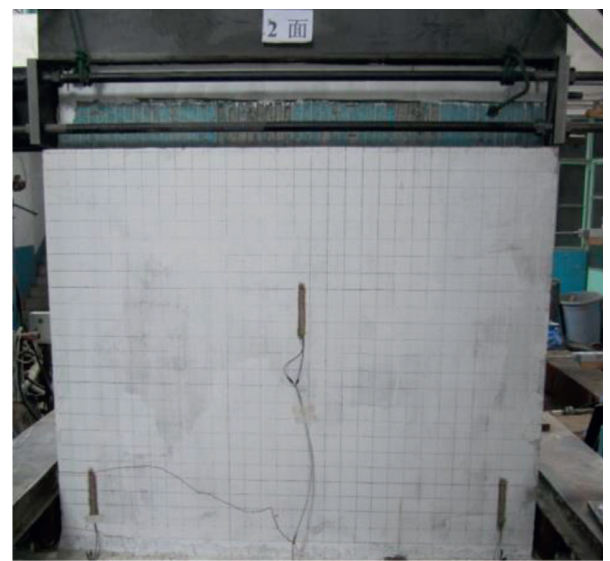

(b)

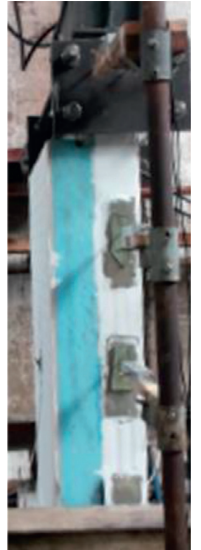

(c)

Figure 4: Experimental apparatus. (a) Positive. (b) Back. (c) Side.

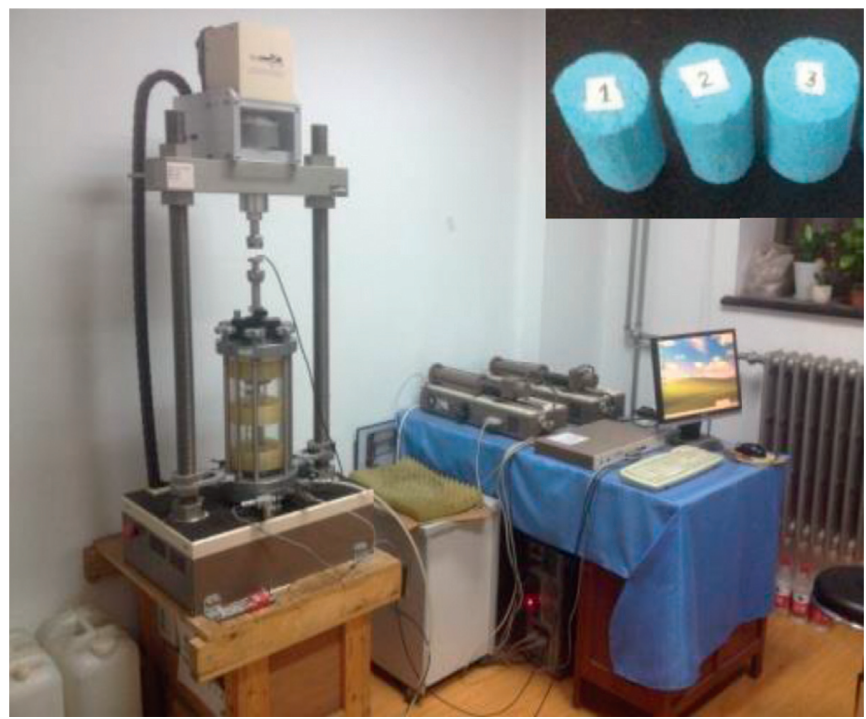

Figure 5: On-site experimental loading instrument.

bearing capacity and stiffness, but also need to have ductility [20]. In the event of an earthquake, strong damping capacity is required to ensure that architectural structures can effectively dissipate earthquake energy. Hence, stiffness, ductility, and damping are three key parameters in seismic design. The center-of-gravity position of thermal-insulation composite plates bearing upside vertical load coincides with the center position of core load-bearing components. The shape, dimension, and reinforcement assembly of core loadbearing components are in full accord with those of conventional composite plates. In this paper, to consider the influence of the thermal insulation system in composite plates, the calculation method, which considers improvement factors on the basis of conventional composite plates, is adopted, in order to simplify the calculation of this composite plate. During calculation, the simplified calculation method described in Ref. [21] is used for conventional composite plates.
3.1. The Improved Factor of Stiffness. The stiffness calculation formula of the composite plate is

$$
E I_{q}=E \frac{\sum I_{i} h_{i}}{\sum h_{i}}
$$

where $E$ is the elastic modulus; $I_{q}$ is the corrected inertia moment; $I_{i}$ and $h_{i}$ are the inertia moment and effective height of some composite plates.

First, the shear elastic modulus of material is determined according to the code for design of concrete structure, i.e., $G=40 \% E$ [22]; then, the simplified calculation formula can be obtained via the weighted average of equivalent stiffness under three kinds of load (inverted triangle distributed load, uniformly distributed load, and top concentrated load):

$$
E I_{\text {eqAvg. }}=E \frac{I_{q}}{1+\left(9 \mu I_{q} / H^{2} A_{q}\right)} \text {. }
$$




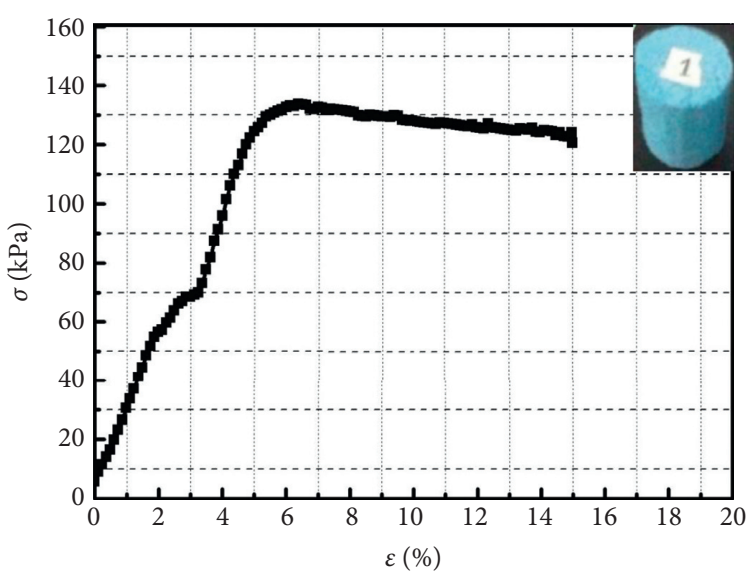

Specimen 1

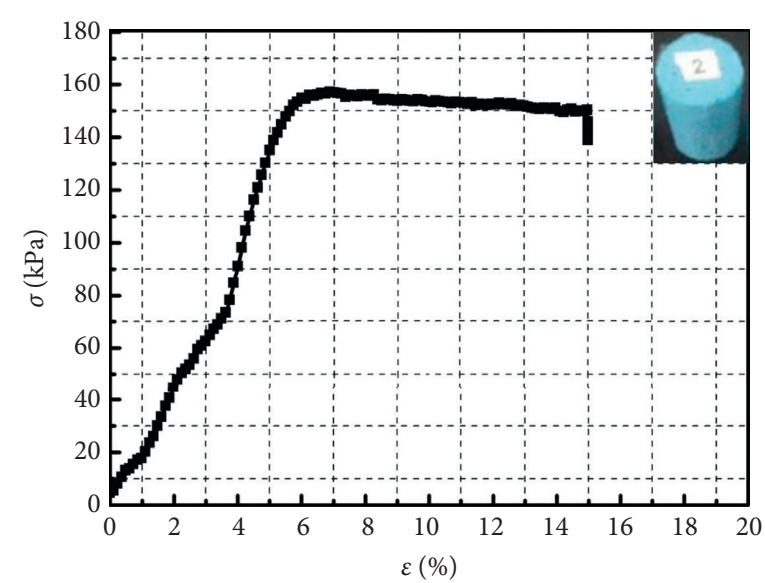

Specimen 2

(a)

(b)

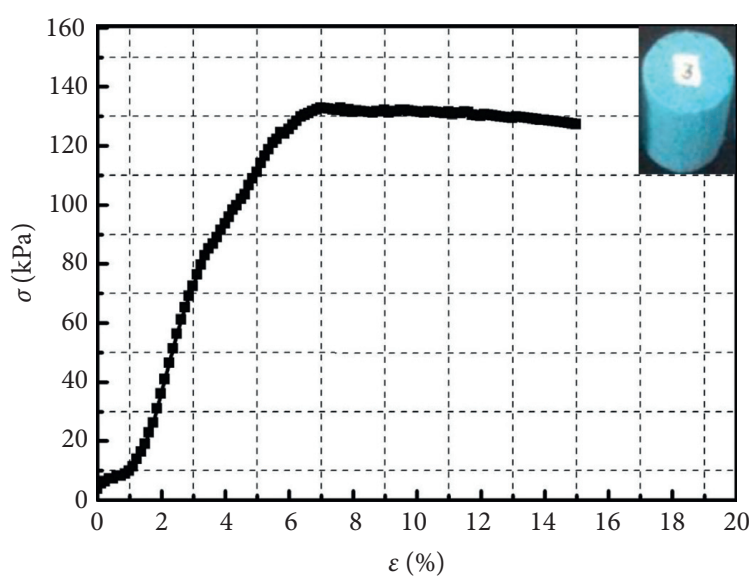

Specimen 3

(c)

FIGURE 6: Stress-strain curve.

According to this formula, the stiffness only correlates to the equivalent the inertia moment $I_{\text {eq }}$. The magnitude of inertia moment is decided only based the basic geometrical dimension of composite plates. The elementary geometrical dimensions of core load-bearing components and conventional composite plates are completely the same, indicating that these two have the same inertia moment. That is, the inertia moment plays the role of a constant in the formula. Hence, the magnitudes of different equivalent wall elastic modulus directly decide the magnitude of wall stiffness, with a direct proportion. In other words, between two kinds of composite plates, the magnitude of their stiffness only differs with a proportionality coefficient, which is also validated by the test results. According to the above analysis results, to fully consider the role played by the thermal insulation system in composite plates and achieve the reasonably simplified calculation and investigation of composite plates, this paper proposes the concept and expression of stiffness improvement factor. This conclusion is crucial to the smooth calculation of thermal-insulation composite plates and other complex structures.
Via calculating the test results of composite plates, the coordinates $(X, Y)$ of key points on the framework curves (crack point $A$, yield point $B$, and ultimate point $C$ ) can be obtained, i.e.,

$$
X=\overline{F_{i}}=\frac{\left|+F_{i}\right|+\left|-F_{i}\right|}{2}, Y=\bar{\delta}_{i}=\frac{\left|+\delta_{i}\right|+\left|-\delta_{i}\right|}{2} .
$$

The stiffness $K_{i}$ at the key point can be obtained as

$$
K_{i}=\frac{\overline{F_{i}}}{\overline{\delta_{i}}} .
$$

Similarly, the related dimensionless coordinate $\left(x_{i}, y_{i}\right)$ is

$$
x_{i}=\frac{\overline{F_{i}}}{\overline{F_{i \max }}}, y_{i}=\frac{\overline{\delta_{i}}}{\overline{\delta_{i \max }}},
$$

where $F_{i}$ and $\delta_{i}$ are the load and displacement of the key point; + and - indicate the positive and negative loading directions; $\bar{F}_{i}$ and $\bar{\delta}_{i}$ are the average values of corresponding load and displacement; $K_{\mathrm{cr}}, K_{y}$, and $K_{u}$ are the cracking, yielding, and ultimate stiffness values. 


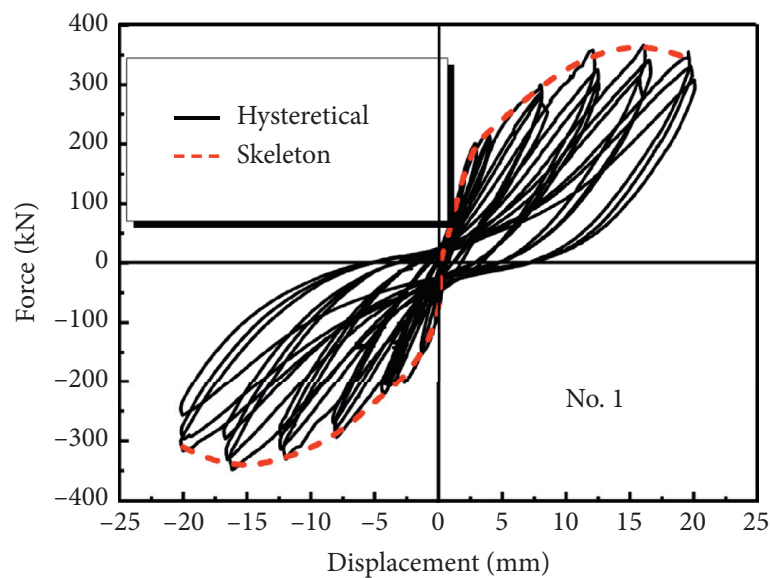

(a)

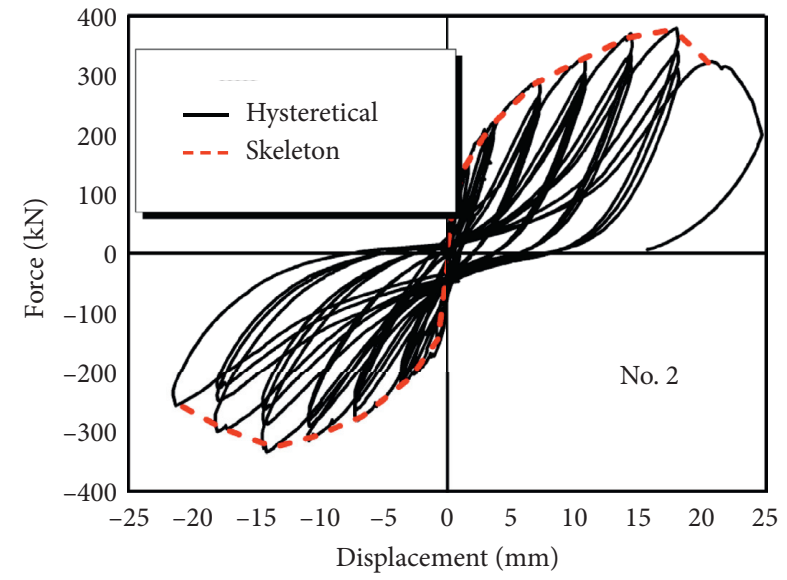

(b)

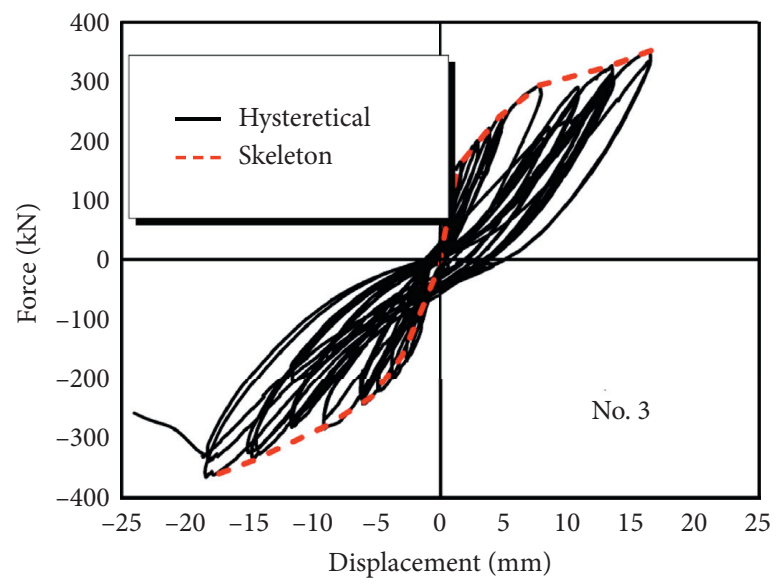

(c)

FIGURE 7: Hysteretic curves of thermal-insulation composite plates.

TABLE 2: Force and displacement.

\begin{tabular}{|c|c|c|c|c|c|c|c|}
\hline Plate type & Specimen no. & $\begin{array}{c}P_{\mathrm{cr}} \\
(\mathrm{kN})\end{array}$ & $\begin{array}{c}\triangle \mathrm{cr} \\
(\mathrm{mm})\end{array}$ & $\begin{array}{c}P_{y} \\
(\mathrm{kN})\end{array}$ & $\begin{array}{c}\triangle y \\
(\mathrm{~mm})\end{array}$ & $\begin{array}{c}P_{u} \\
(\mathrm{kN})\end{array}$ & $\begin{array}{c}\triangle u \\
(\mathrm{~mm})\end{array}$ \\
\hline \multirow{4}{*}{ Without thermal insulation system } & 1 & 60.46 & 0.84 & 212.60 & 3.68 & 311.85 & 11.90 \\
\hline & 2 & 60.11 & 0.69 & 206.40 & 3.50 & 305.02 & 12.42 \\
\hline & 3 & 64.74 & 0.61 & 211.50 & 3.07 & 327.07 & 11.85 \\
\hline & Avg. & 61.77 & 0.71 & 210.17 & 3.42 & 314.65 & 12.06 \\
\hline \multirow{4}{*}{ With thermal insulation system } & 1 & 78.70 & 0.85 & 209.07 & 4.02 & 369.63 & 16.08 \\
\hline & 2 & 69.43 & 0.75 & 220.25 & 4.11 & 377.71 & 17.72 \\
\hline & 3 & 71.57 & 0.83 & 215.76 & 4.16 & 366.45 & 18.13 \\
\hline & Avg. & 73.23 & 0.81 & 215.03 & 4.10 & 371.26 & 17.31 \\
\hline Improvement & & 0.19 & 0.14 & 0.02 & 0.20 & 0.18 & 0.44 \\
\hline
\end{tabular}

Notes: $P_{\text {cr }}$ denotes the cracking load; $\Delta$ cr denotes the cracking displacement; $P_{y}$ denotes the yielding load; $\Delta y$ denotes the yielding displacement; $P_{u}$ denotes the ultimate load; $\Delta u$ denotes the ultimate displacement.

By connecting the initial origin point, point $A$, point $B$, and point $C$ via straight lines, the dimensionless stiffnessdisplacement trilinear model can be obtained. Afterwards, the tangent value of the angle between each broken line and the $x$-axis is defined as the stiffness evaluation factor of the composite plate and expressed as $k_{i}$. That is, the stiffness evaluation factor of the composite plate before cracking, before yielding, and reaching ultimate value is $k_{\mathrm{cr}}, k_{y}$, and $k_{u}$, respectively. By defining the ratio of the stiffness evaluation factors of these two types of composite plates as the stiffness improvement factor, there is

$$
\lambda_{i}=\frac{k_{i}^{\prime}}{k_{i}}
$$




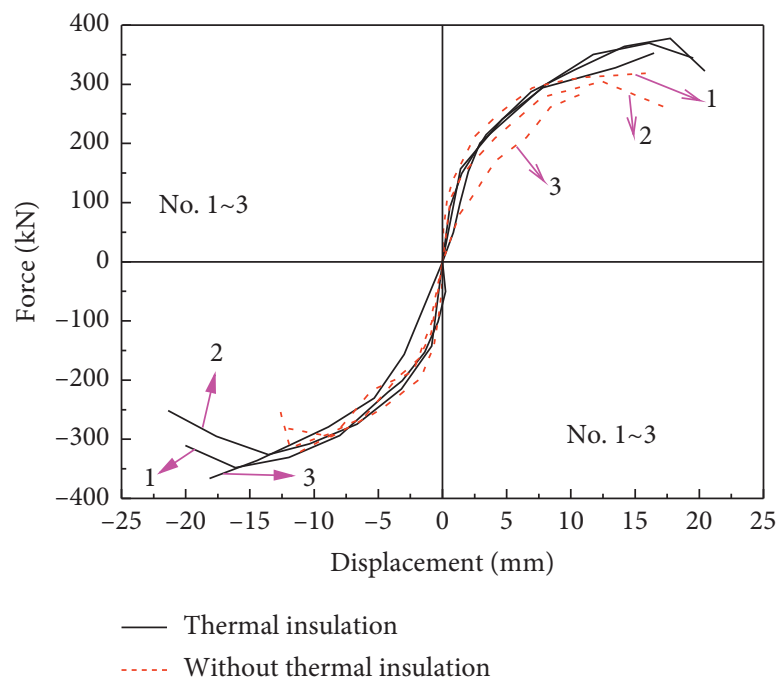

FIgURE 8: Comparison of skeleton curves.

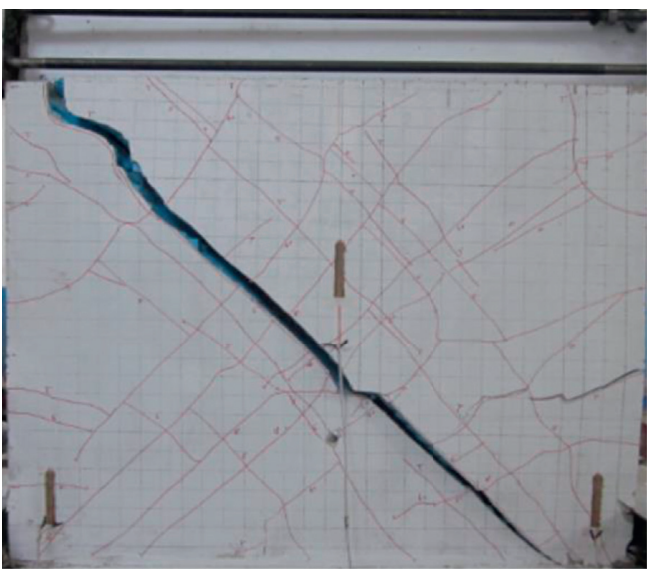

(a)

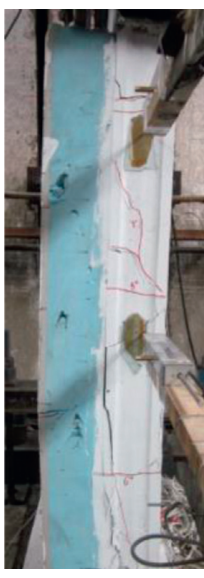

(b)

Figure 9: Destruction graph of thermal-insulation composite plates. (a) Back. (b) Side.

TABLE 3: The ductility coefficient of the sample.

\begin{tabular}{lcccccc}
\hline & \multicolumn{3}{c}{ Without thermal } & \multicolumn{4}{c}{ With thermal } \\
Specimen no. & \multicolumn{2}{c}{$\begin{array}{c}\text { insulation system } \\
\text { insulation system }\end{array}$} \\
& 1 & 2 & 3 & 1 & 2 & 3 \\
\hline Ductility coefficient $\mu$ & 3.23 & 3.55 & 3.86 & 4.00 & 4.31 & 4.36 \\
Avg. & & 3.55 & & & 4.22 & \\
\hline
\end{tabular}

where $k_{i}^{\prime}$ indicates the stiffness evaluation factor of composite plate with the thermal-insulation system.

3.2. The Improved Factor of Damping. During analyzing the energy dissipation of composite the plate, when the deformation degree is relatively large, the deformation gradually goes over the elastic range and enters the stage of elastoplastic deformation. That is, after unloading, there is still part of deformation that cannot recover completely, indicating that some residual deformation occurs during loading, and some energy is dissipated. This is the so-called elastoplasticplastic dissipated energy in earthquake proofing construction. Earthquake proofing tests of composite plates usually follow the quasistatic seismic test method described in the regulation for building seismic testing method [23]. During testing, the velocity and acceleration are both considered as zero, i.e.,

$$
m \ddot{u}=c \dot{u}=0,
$$

where $\dot{u}$ and $\ddot{u}$ are the velocity and acceleration, respectively; $m$ is the mass of the composite plate system; $c$ is the viscous damping coefficient.

By recording the applied load and plate-end deformation, a hysteresis loop energy dissipation representative diagram reflecting the load-deformation relationship can be obtained, as shown in Figure 10. 


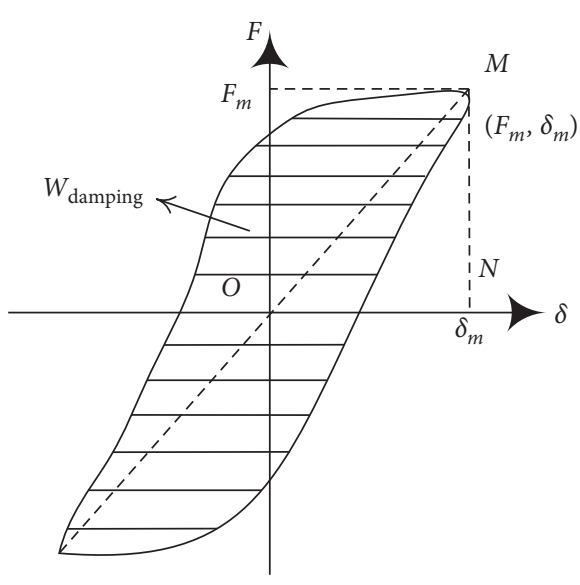

(a)

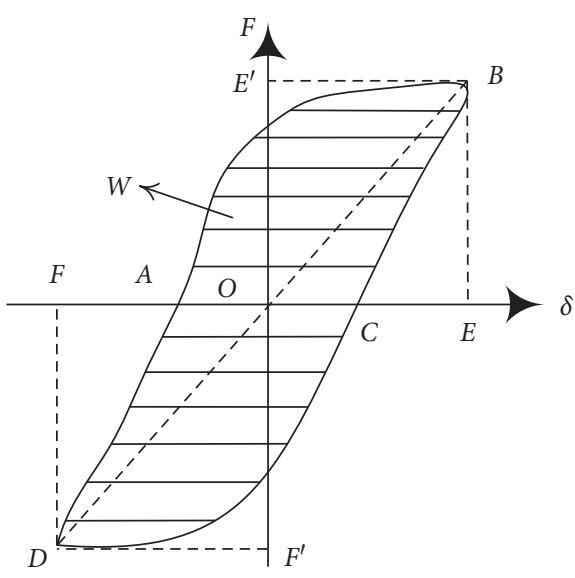

(b)

FIgURE 10: Hysteresis loop energy dissipation representative diagram.

$F$ and $\delta$ are the load and displacement of the top point; $F_{m}$ and $\delta_{m}$ are the averaged peak values of the top point load and displacement within one hysteresis loop; $\zeta$ stands for the equivalent viscous damping ratio.

As widely recognized, within one motion period of dynamic structural response, the dissipated energy is equal to the area surrounded by the hysteresis loop. Under the influence of equivalent viscous damping, the energy dissipated by the composite plate within one period is $W_{\mathrm{d}}$, i.e.,

$$
W_{\text {damping }}=4 \pi \zeta S_{\triangle O M N} .
$$

As shown in Figure 5(a), the area of the triangle OMN $S_{\triangle O M N}$ is

$$
S_{\triangle \mathrm{OMN}}=\frac{1}{2} F_{m} \delta_{m}=\frac{1}{2} k \delta_{m}^{2},
$$

where $k$ stands for the average stiffness during elastoplastic deformation, i.e.,

$$
k=\frac{F_{m}}{\delta_{\mathrm{m}}},
$$

Hence, it can be obtained that

$$
W_{\text {damping }}=2 \pi \zeta k \delta_{m}^{2} .
$$

Discussing from the aspect of energy dissipation, the damping dissipated energy can be completely considered as being equal to the elastoplastic dissipated energy. As shown in Figure 7 , there is

$$
W_{\text {damping }}=W \text {, }
$$

where

$$
\left\{\begin{array}{l}
S_{\triangle O M N}=\frac{1}{2}\left(S_{\triangle B E O}+S_{\triangle D F O}\right), \\
F_{m}=\frac{1}{2}\left(F_{B}+F_{D}\right), \\
\delta_{m}=\frac{1}{2}\left(\delta_{B}+\delta_{D}\right) .
\end{array}\right.
$$

Hence,

$$
\zeta=\frac{1}{2 \pi} \frac{W}{k \delta_{m}^{2}} .
$$

After $\zeta$ is determined, under the seismic influence, the motion equation of the composite plate system can be directly constructed, i.e., $\ddot{u}+2 \zeta \omega \dot{u}+\omega^{2} u=-\ddot{u}_{g}$ where

$$
\omega=\sqrt{\frac{k}{m}} .
$$

Thus, the nonlinear calculation of the composite plate system (elastoplastic energy) can be transferred into the equivalent linear calculation. That is, the so-called equivalent linearization method can also obtain similar results. By substituting $k$ and $S_{\triangle O M N}$ into the equation, we can acquire that

$$
\zeta=\frac{1}{2 \pi} \frac{S_{\triangle A B C}+S_{\triangle C D A}}{S_{\triangle B E O}+S_{\triangle D F O}}=h_{e},
$$

$h_{e}$ can be decided according to the test results. The existence of the thermal insulation system leads to the difference of $h_{e}$ values of two composite plates. According to the hysteresis curves obtained via tests, $h_{e}$ values of two composite plates corresponding to $1 \Delta y, 2 \Delta y$, and $3 \Delta y$ can be obtained, respectively. The ratio is defined as the damping evaluation coefficient $\xi_{i}$, i.e.,

$$
\xi_{i}=\frac{h_{e i}^{\prime}}{h_{e i}},
$$

where $i$ is the magnification; $h_{e i}^{\prime}$ is the damping coefficient of the thermal-insulation composite plate. The average value of $\xi_{i}$ is defined as the damping improvement factor $\psi$, where $n$ stands for the total number of the damping evaluation coefficients, i.e.,

$$
\psi=\frac{\sum \xi_{i}}{n} .
$$




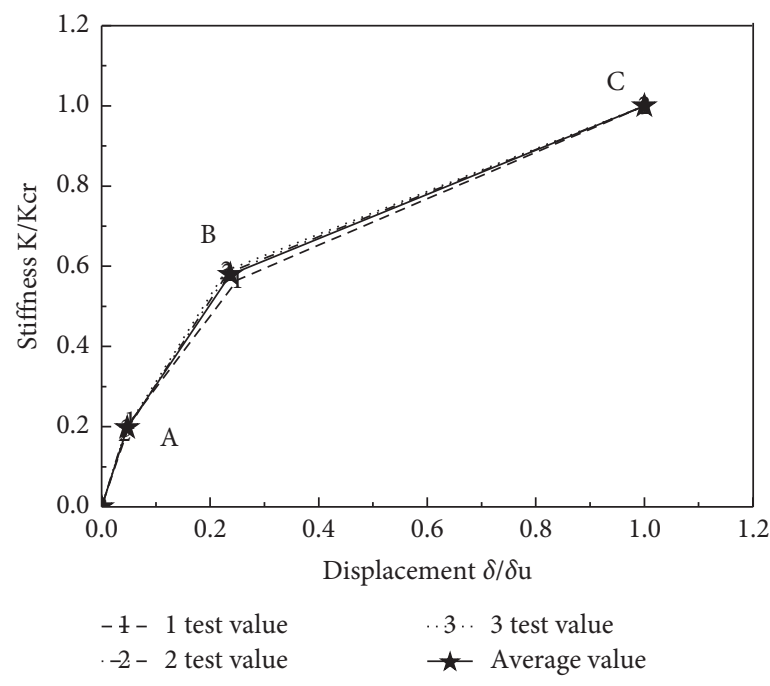

(a)

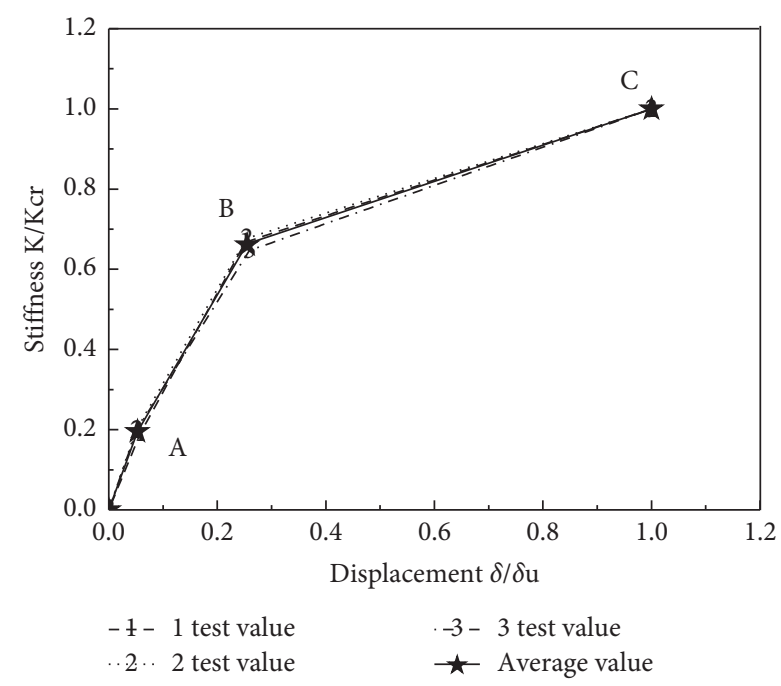

(b)

Figure 11: Nondimensional stiffness-displacement relation. (a) Conventional composite plate. (b) Composite plate considering thermal insulation system.

\section{Example Analyses}

\subsection{Material Constants and Improvement Factors}

4.1.1. Material Properties. The stress states of core stress components in composite plates considering thermal insulation system are similar to those in conventional composite plates. The material property parameters of core stress components can be acquired according to material (plaster, gypsum, and so on) test results, as well as the equivalent simplified calculation formula of conventional composite plates reported in Ref. [21]. That is, the elastic moduli in the $x$-direction and $y$-direction are $22248.41 \mathrm{MPa}$ and $21622.17 \mathrm{MPa}$, respectively; the $x y$ shear elastic modulus is $8658.20 \mathrm{MPa}$; the Poisson ratio is 0.196 .

4.1.2. The Improved Factor of Stiffness. Average value fitting is conducted on the nondimensional stiffness-displacement triple lines of two types of composite plates, with the results displayed in Figure 11. The stiffness evaluation factors of different sections are calculated. As for conventional composite plates, $k_{\mathrm{cr}}=3.68, k_{y}=2.32$, and $k_{u}=0.45$; for composite plates considering thermal insulation system, $k_{\mathrm{cr}}{ }^{\prime}=4.20, k_{y}{ }^{\prime}=2.01$, and $k_{u}{ }^{\prime}=0.55$. Finally, the stiffness improvement factors are obtained as $\lambda_{\mathrm{cr}}=1.14, \lambda_{y}=1.00$, and $\lambda_{u}=1.23$. It is regulated that when individually settling single sections, the stiffness improvement factor should be greater than 1. The advantage of this treating method is that although this section cannot be improved, this section will not decrease, which agrees with the test results.

4.1.3. Calculation Result of Damping Improvement Factor. By conducting data treatment and calculation on the seismic test results of six specimens prepared from the two types of composite plates, related $H_{e}$ and $\xi$ can be obtained, with detailed results listed in Table 4 . By substituting $\xi$ into the calculation formula of $\psi$, the damping improvement factor is calculated to be 1.089 .

4.2. Model Establishment and Solution. Figure 12 shows the $3 \mathrm{D}$ calculation model of the equivalent specimen of the thermal-insulation composite wallboard mainly consisting of three parts: middle equivalent wall (SOLID65 element), and distributive beam and fixed beam with relatively large stiffness in the top and bottom (SOLID45 element). The vertical and horizontal rebars in the wall are meshed using LINK8 bar element [23], with embedded and public nodes. According to the test results, during the loading process of all specimens, the wall fractures, while both the fixed beam and distributive beam are well preserved before and after the test. Hence, to ensure the smooth proceeding of calculation, the material properties are increased to avoid the premature failure of the distributive beam and fixed beam. The simplified stress-strain curve of the wall is shown in Figure 13. The ideal elastoplastic model is utilized for rebar [24]. The boundary condition is set as follows: the bottom and two ends of the fixed beam are fixed. The load applied consists of two parts: a vertical load, which simulates the self-weight of the upper structure and is applied using uniformly distributed area load, and a horizontal load, which simulates the horizontal earthquake action on the wall. In the initial stage of loading, a single cycle can be used to control the displacement load since the wall stressed deformation is small. After yielding, the single cycle is changed into three cycles per stage [25], until wall failure. The displacement control is set by referring to the experimental value of specimen 2 .

4.3. Results Analysis. Based on the effective area of the hysteresis loop in Figure 14, it is implied that the calculation results are slightly greater than the test results. Meanwhile, the global hysteresis curves imply that the calculation results are relatively 
TABle 4: Damping data sheet.

\begin{tabular}{|c|c|c|c|c|c|c|c|c|c|c|c|}
\hline \multirow{2}{*}{ Composite plate type } & \multirow{2}{*}{ Wall no. } & \multicolumn{6}{|c|}{ he } & \multicolumn{3}{|c|}{$\zeta$} & \multirow{2}{*}{$\psi$} \\
\hline & & $1 \triangle y$ & Avg. & $2 \Delta y$ & Avg. & $3 \triangle y$ & Avg. & $\zeta_{1}$ & $\zeta_{2}$ & $\zeta_{3}$ & \\
\hline \multirow{3}{*}{ Without thermal insulation system } & 1 & 0.09 & & 0.09 & & 0.10 & & \multirow{6}{*}{1.143} & \multirow{6}{*}{1.125} & \multirow{6}{*}{1.000} & \multirow{6}{*}{1.089} \\
\hline & 2 & 0.07 & 0.07 & 0.08 & 0.08 & 0.09 & 0.09 & & & & \\
\hline & 3 & 0.06 & & 0.07 & & 0.07 & & & & & \\
\hline \multirow{3}{*}{ With thermal insulation system } & 1 & 0.09 & \multirow{3}{*}{0.08} & 0.08 & \multirow{3}{*}{0.09} & 0.09 & \multirow{3}{*}{0.09} & & & & \\
\hline & 2 & 0.09 & & 0.09 & & 0.09 & & & & & \\
\hline & 3 & 0.08 & & 0.09 & & 0.09 & & & & & \\
\hline
\end{tabular}

Notes: $h_{e}$ denotes the equivalent viscous damping coefficient; $\zeta$ denotes the damping evaluation coefficient; $\psi$ denotes the damping improvement factor.

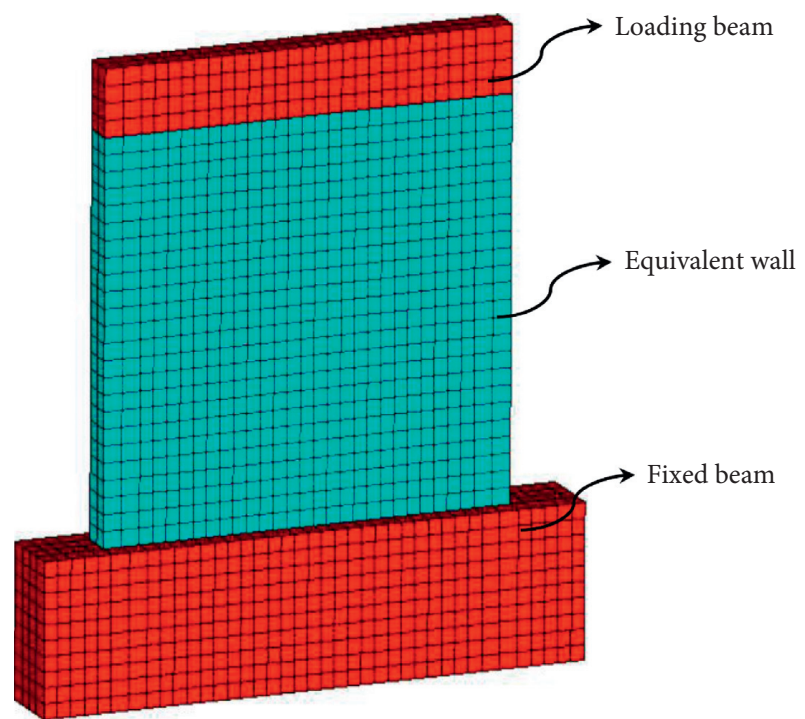

Figure 12: 3D model.

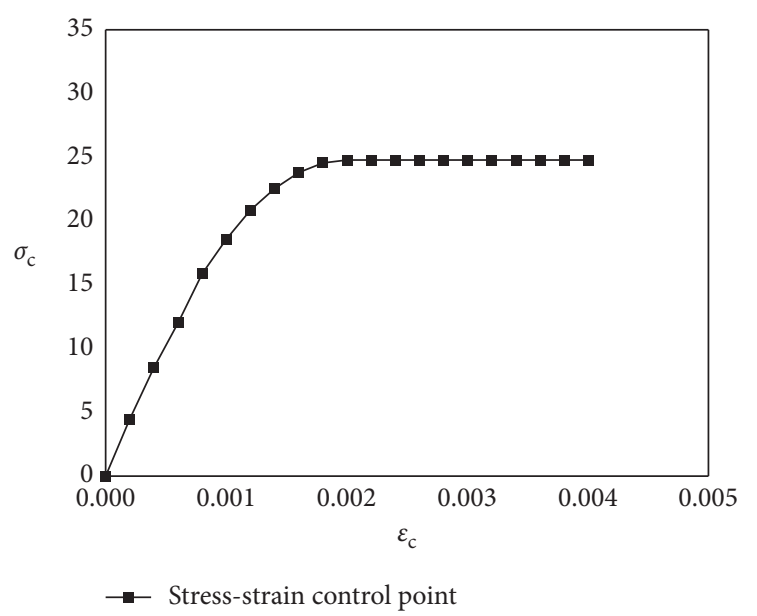

FIGURE 13: Stress-strain relationship.

plump. The framework curve in Figure 15 indicates that the calculation results are greater than test results. The cause of this phenomenon is discussed as follows. During simulation, the slippage between the insulation plate and wall is ignored. The wall material is ideal, without considering errors generated during actual production (insufficient vibration of plaster and concrete), or defects produced during transportation and installation (such as damage of wall corner and wall side).

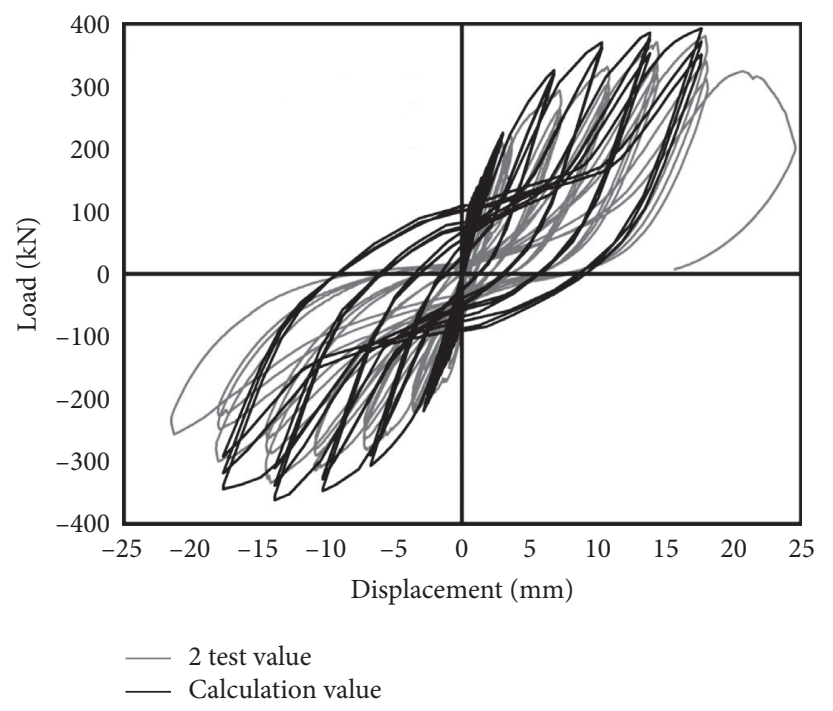

FIgURE 14: Comparison of hysteresis curves.

Via comparing the load and displacement of key point, it is indicated that the calculation results agree with the test results, as listed in Table 5. Based on error analysis, the local error and global error are both controlled within 5\%, which meets the requirement of engineering calculation. The research results indicate that it is feasible to convert composite plates, which have complex structures and are difficult to be modeled and calculated, into the equivalent wall with similar properties, and utilize the simplified calculation method of improvement factor to conduct calculation analysis. This method can also be applied in the calculation analysis of more complex global structures.

As we all know, the seismic performance test research is a destructive test. Under the action of simulated seismic force, the composite plate has gone through the elastic stage and the elastoplastic stage. After unloading, there is still part of deformation that cannot recover completely, indicating that some residual deformation occurs during loading, and some energy is dissipated. In the simulation calculation of components, the influence of nonlinearity on the solution must also be considered. If not considered, the specimen will not be damaged. It is difficult to derive and solve the theory of nonlinearity. In order to solve this problem, this article uses the equivalent linearization method. Thus, the nonlinear calculation of the composite plate system (elastoplastic 


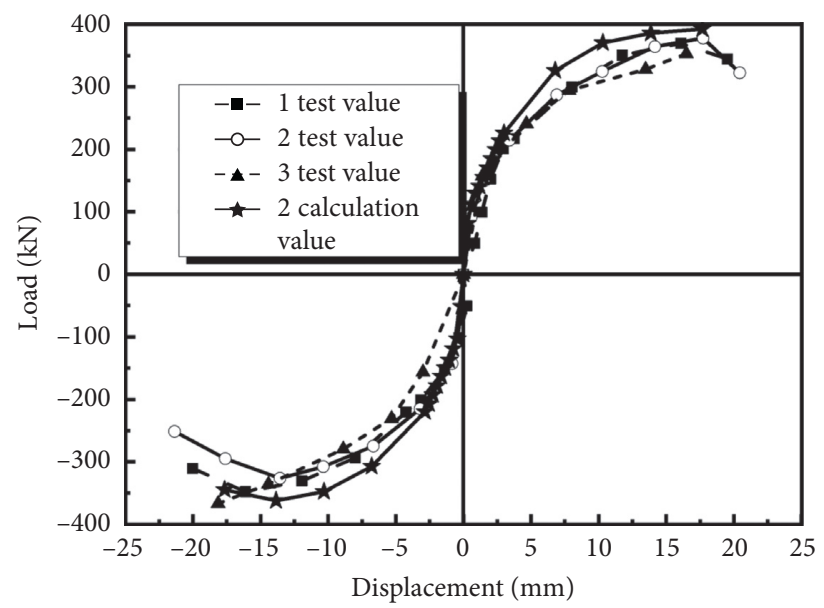

Figure 15: Comparison of framework curves.

TABLE 5: Comparison of test and calculation results.

\begin{tabular}{|c|c|c|c|c|c|c|c|}
\hline Result types & Specimen no. & $\begin{array}{c}P_{\mathrm{cr}} \\
(\mathrm{kN})\end{array}$ & $\begin{array}{c}\triangle_{\mathrm{cr}} \\
(\mathrm{mm})\end{array}$ & $\begin{array}{c}P_{y} \\
(\mathrm{kN})\end{array}$ & $\begin{array}{c}\triangle \mathrm{y} \\
(\mathrm{mm})\end{array}$ & $\begin{array}{c}P_{u} \\
(\mathrm{kN})\end{array}$ & $\begin{array}{c}\triangle \mathrm{u} \\
(\mathrm{mm})\end{array}$ \\
\hline \multirow{4}{*}{ Test value } & 1 & 78.7 & 0.85 & 209.07 & 4.02 & 369.63 & 16.08 \\
\hline & 2 & 69.43 & 0.75 & 220.25 & 4.11 & 377.71 & 17.72 \\
\hline & 3 & 71.57 & 0.83 & 215.76 & 4.16 & 366.45 & 18.13 \\
\hline & Avg. & 73.23 & 0.81 & 215.03 & 4.1 & 371.26 & 17.31 \\
\hline Calculation value & 2 & 72.57 & 0.78 & 224.04 & 3.98 & 382.49 & 17.66 \\
\hline Local error (\%) & & 4.52 & 4 & 1.72 & 3.16 & 1.27 & 0.34 \\
\hline Global error (\%) & & 0.91 & 3.7 & 4.19 & 2.85 & 3.02 & 2.02 \\
\hline
\end{tabular}

energy) can be transferred into the equivalent linear calculation. By using this method to analyze the composite board by example, the calculation effect is better.

The same conclusion can be drawn by comparing the test results with the calculated results. The damage occurred at the foot position of the composite wallboard specimens. The gypsum-concrete composite material at this location was crushed, and the steel bars were bent. The test piece showed good seismic performance. It is suggested that composite wall panels can be popularized and used in actual projects. The composite wallboard proposed in this article has the advantages of energy saving and environmental protection and meets the current requirements of countries around the world to vigorously encourage the development of green buildings.

\section{Conclusions}

By investigating the testing and simplified calculation methods for thermal-insulation composite plates, the following conclusions can be drawn:

(1) Focusing on the calculation difficulty of complex composite plates, a simplified calculation method, which deduces the improvement factor from test results, is proposed in this paper. The influence of the nonstructural thermal insulation system on the composite plate is considered, and the successive modeling and analysis of the global structure of composite plate are completed. In addition, this method can also be used for the calculation and research of thermal insulation composite wallboard samples, and the calculation process is more convenient than ordinary calculation methods.

(2) By analyzing the test results of two types of composite plates with/without thermal insulation systems, theoretical deduction of the simplified calculation method of improvement factors is carried out. The calculation formulas of stiffness and damping are developed. Through comparative analysis of theoretical derivation and experiment, the correctness has been proved.

(3) Under the influence of cyclic loading, simulation and calculation of composite plates are conducted by using the simplified calculation method of improvement factor. The obtained calculation results agree well with the test results. The errors are all within engineering tolerance ranges. Thus, the accuracy and reliability of this method are validated. Compared to the calculation method described in Ref. [21], the calculation method proposed in this study significantly reduces the calculation difficulty and workload. The research results can provide important references for the study of similar plates and structures.

\section{Data Availability}

The samples in this article are manufactured in a prefabricated component factory. The tests were done in the 
structural laboratory of Henan University. The operation test is conducted in accordance with the test specification, and the result is reliable. On the basis of the experiment, the theoretical derivation is carried out, and the result is achieved by calculation. By comparing the calculated results with the test results, the reliability of the results has been verified. The research results have high engineering application value.

\section{Conflicts of Interest}

The authors declare no conflicts of interest.

\section{Authors' Contributions}

Shaochun Ma performed the tests, analyzed the data, and wrote the paper. Hongyuan Fang conceived and supervised the work. All authors contributed to the conclusion of the thesis.

\section{Acknowledgments}

The authors would like to express their heartfelt gratitude to the financial support by the Science Technology of the Ministry of Housing and Urban-Rural Development (No. 2018-K9-065), China Postdoctoral Science Foundation funded project (No. 2018M632805), Key Scientific and Technological Project of Henan Province (No. 212102310932), and Key Scientific and Technological Project of Kaifeng City (No. 2001010).

\section{References}

[1] H. Lee, S. Yang, S. Wi, and S. Kim, “Thermal transfer behavior of biochar-natural inorganic clay composite for building envelope insulation," Construction and Building Materials, vol. 223, pp. 668-678, 2019.

[2] S. Ma and N. Jiang, "Experimental investigation on the seismic behavior of a new-type composite interior wallboard," Materials and Structures, vol. 49, no. 12, pp. 5085-5095, 2016.

[3] M. J. Abden, Z. Tao, and Z. Pan, "Inclusion of methyl stearate/ diatomite composite in gypsum board ceiling for building energy conservation," Applied Energy, vol. 259, pp. 1-14, 2020.

[4] D. Wu, Y. Yamazaki, S. Sawada, H. Sakata et al., "Shaking table tests on 1/3-scale model of wooden horizontal hybrid structure," Journal of Structural Engineering, vol. 144, no. 8, 2018.

[5] J. H. Park, Y. Kang, J. Lee, S. Wi, J. D. Chang, and S. Kim, "Analysis of walls of functional gypsum board added with porous material and phase change material to improve hygrothermal performance," Energy and Buildings, vol. 183, pp. 803-816, 2019.

[6] S. C. Ma, P. Bao, X. L. Jiang et al., "Experiment on anti-seismic performance of assembled energy-saving shear wall," Journal of Lanzhou University of Technology, vol. 45, no. 3, pp. 113117, 2019.

[7] Y. Dias, P. Keerthan, and M. Mahendran, "Fire performance of steel and plasterboard sheathed non-load bearing LSF walls," Fire Safety Journal, vol. 103, pp. 1-18, 2019.

[8] M. Khoukhi, N. Fezzioui, B. Draoui, and L. Salah, "The impact of changes in thermal conductivity of polystyrene insulation material under different operating temperatures on the heat transfer through the building envelope," Applied Thermal Engineering, vol. 105, pp. 669-674, 2016.

[9] A. D. Lee, P. Shepherd, M. C. Evernden, and D. Metcalfe, "Optimizing the architectural layouts and technical specifications of curtain walls to minimize use of aluminium," Structures, vol. 13, pp. 8-25, 2018.

[10] X. L. Lv, D. Y. Zhou, S. M. Li et al., Seismic Design Theory and Example, Tongji University Press, Beijing, China, 2011.

[11] S. C. Ma, P. Bao, and N. Jiang, "Experimental study of gypsum-concrete dense-column composite boards with external thermal insulation systems," Applied Scineces, vol. 10, no. 6, pp. 1-12, 2020.

[12] Y. Hou, X. Cheng, S. Liu, C. Liu, and H. Zhang, "Experimental study on upward flame spread of exterior wall thermal insulation materials," Energy Procedia, vol. 66, pp. 161-164, 2015.

[13] G. Vasconcelos, E. Poletti, E. Salavessa, A. M. P. Jesus, P. B. Lourenço, and P. Pilaon, "In-plane shear behaviour of traditional timber walls," Engineering Structures, vol. 56, no. 1, pp. 1028-1048, 2013.

[14] X. H. Zhang, R. H. Wang, M. Xu et al., "Anti-seismic experimental study on composite wall with one-sided cladding of strawboard," Journal of Building Materials, vol. 22, no. 6, pp. 908-916, 2019.

[15] S. C. Ma, L. H. Li, and P. Bao, "Seismic performance test of double-row reinforced ceramsite concrete composite wall panels with cores," Applied Sciences, vol. 11, no. 6, pp. 1-19, 2021.

[16] E. Ramírez, P. B. Lourenço, and M. D’Amato, "Seismic assessment of the Matera cathedral," in Proceedings of SAHC 2018, 11th International Conference on Structural Analysis of Historical Constructions, pp. 1346-1354, Cusco, Perù, September 2018.

[17] M. Deng, Z. Dong, and P. Ma, "Cyclic loading tests of flexuralfailure dominant URM walls strengthened with engineered cementitious composite," Engineering Structures, vol. 194, pp. 173-182, 2019.

[18] D. D. Fuentes, P. A. Baquedano Julià, M. D’Amato, and M. Laterza, "Preliminary seismic damage assessment of Mexican churches after september 2017 earthquakes," International Journal of Architectural Heritage, pp. 1-21, 2019.

[19] Chinese National Standards, Specification of Testing Methods for Earthquake Resistant Building, Architecture \& Industry Press of China, Beijing, China, 1997.

[20] X. R. Li, "Non-linear damping properties and dynamic response of frp-confined reinforced concrete columns," Doctoral dissertation, Beijing Jiaotong University, Beijing, China, 2013.

[21] N. Jiang and S. Ma, "Simplified calculation model and experimental study of latticed concrete-gypsum composite panels," Materials, vol. 8, no. 10, pp. 7199-7216, 2015.

[22] Chinese National Standards, Code for Design of Concrete Structures. GB50010-2010, Architecture \& Industry Press of China, Beijing, China, 2011.

[23] X. M. Wang, ANSYS Numerical Analysis of Engineering Structures, China Communications Press, Beijing, China, 2007.

[24] J. H. Bi and H. Wang, Engineering Elastic-Plastic Mechanics, Tianjin University Press, Tianjin, China, 2008.

[25] W. Chen and J. Ye, "A new simplified calculation model of CFS composite exterior walls under fire conditions," Structures, vol. 22, pp. 53-64, 2019. 